\title{
Mullins Receives Von Hippel Award
}

The Materials Research Society's highest honor, the Von Hippel Award, will be presented this year to William W. Mullins, university professor emeritus of materials science and engineering at CarnegieMellon University (CMU). He received the award "for pioneering and profound contributions to the understanding of grain boundary motion, morphological stability, the structure of surfaces and interfaces, and flow and diffusion as stochastic phenomena."

The Von Hippel Award is given annually to an individual in recognition of outstanding contributions to interdisciplinary research on materials.

Mullins was recognized for his major influence in materials science, particularly in the four categories cited above, with particular attention to grain boundary kinetics, morphological instabilities and surface topological changes, and making a connection between atomistic and phenomenological descriptions of step structures on surfaces. His early work treated interface motion under carefully controlled driving forces and eventually led to a much improved understanding of solid state capillarity and to a technique for quantitative and reliable measurements of self-diffusion coefficients on surfaces at high temperatures. Mullins's formulation of a theory for instability finally led to a deeper understanding of the origin of dendrites and other such shapes, as well as the inhomogeneities that are incorporated into crystals.

He is known as a superb teacher and lecturer, and is well-known worldwide for seminars of particular clarity, with a gift for extracting, in its barest simplicity, the essence of a phenomenon.

Mullins's work is based on an interdisciplinary approach, and represents a blend of the principles and techniques of physics, applied mathematics, and materials engineering. Most of his research has become the "bread and butter" of modern materials science and engineering. He has developed or strongly influenced work in grain boundary grooving, scratch decay, field emitter tip blunting, sintering, morphological instability, similarity in scaling laws for grain growth, influence of bias on the statistics of diffusion, and random walk kinetics of granular materials.

In an early paper, Mullins idealized

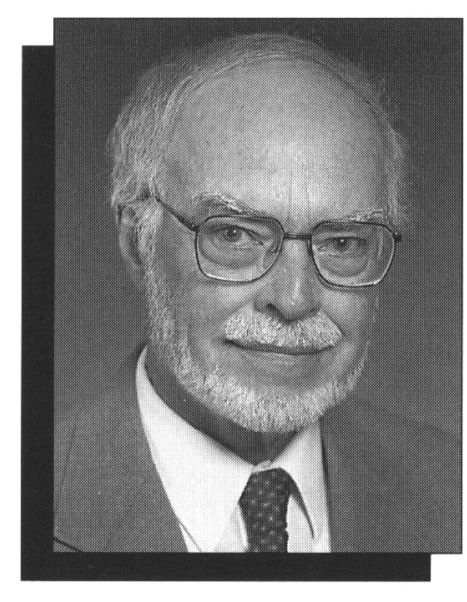

two-dimensional grain growth in what is today called the von Neumann-Mullins "N-6" topological theory of grain growth, with " $N$ " the number of sides of a grain. He demonstrated that the growth rate of a two-dimensional grain executing isotropic growth or shrinkage at each of its edges is solely dependent on the number of its vertices or edges. He was the first to show that metallurgical grains comprising a film or sheet, or other nearly two-dimensional arrangements will exhibit shrinkage if they have fewer than six sides, and growth if they have more than six sides. Six-sided grains neither shrink nor grow but wait until some topological event occurring in the near neighborhood of the grain changes its number of vertices or sides, then growth will occur.

In the early 1960s, Mullins and CMU colleague Robert Sekerka showed that the so-called linear stability theory could be used to analyze the morphological stability of a moving phase boundary, and that beyond some critical speed of solidification or below some critical value of the temperature gradient, the interface would undergo a radical shape change.

In another early paper, Mullins and his student E.E. Gruber developed the first statistical-mechanical analysis of steppedcrystal surfaces that led to an understanding of the anisotropy of crystalline-surface energy and of surface roughening.

Mullins's 1986 paper on statistical selfsimilarity opened the way to understand why complex phase morphologies, like real-world metallurgical microstructures, undergo self-similar coarsening under such wide ranges of physical and geometrical conditions. He showed how robust self-similar (scaling) behavior is in materials systems, without resorting to any restrictive geometrical assumptions about the phase shapes encountered, such as the need for assuming "spherical particles" or "cylindrical precipitates."

Mullins received his $\mathrm{PhB}, \mathrm{MS}$, and $\mathrm{PhD}$ degrees in physics from the University of Chicago in 1949, 1951, and 1955, respectively. He joined the Westinghouse Research Laboratories as a research physicist in 1955, and became an advisory physicist in 1959. He joined the Carnegie Institute of Technology - the predecessor of Carnegie-Mellon University-as an associate professor of metallurgical engineering in 1960.

He became professor and head of the Department of Metallurgy and Materials Science in 1963, and was dean of the then College of Engineering and Science from 1966 to 1970 . Mullins was professor of applied science from 1970 to 1985 , and directed the Center for the Joining of Materials from 1982 to 1985 . He was named university professor of applied science in 1985, and was awarded emeritus status in 1992.

Mullins has received numerous awards and honors, including election to the National Academy of Sciences in 1984. He received a Guggenheim Fellowship and a Fulbright Grant in 1961, and was awarded the Mathewson Gold Medal from the American Institute of Mining, Metallurgical and Petroleum Engineers (AIME) in 1963. In 1990, he received a professional achievement citation from the University of Chicago Alumni Association, and was given the Humboldt Research Award in 1992, and the Robert Franklin Mehl Award in 1994.

He is also a fellow of The Minerals, Metals and Materials Society of AIME, and a member of the American Physical Society, the American Association for the Advancement of Science, Tau Beta Pi, and Sigma Xi.

The Von Hippel Award will be presented to Mullins at the 1995 MRS Fall Meeting during the awards ceremony Wednesday, November 29, at 6:00 p.m., Salon E at the Boston Marriott Hotel, after which he will present his talk, "Remarks on the Evolution of Materials Science." NEWS TO: 